\title{
Clinical malaria among pregnant women on combined insecticide treated nets (ITNs) and intermittent preventive treatment (IPTp) with sulphadoxine-pyrimethamine in Yaounde, Cameroon
}

Robinson Enow Mbu ${ }^{1 *}{ }^{*}$, William Ako Takang ${ }^{3 \dagger}$, Hortence Jeanne Fouedjio ${ }^{1 \dagger}$, Florent Ymele Fouelifack ${ }^{2 \dagger}$, Florence Ndikum Tumasang ${ }^{2+}$ and Rebecca Tonye ${ }^{2+}$

\begin{abstract}
Background: Malaria remains a burden for pregnant women and the under 5. Intermittent preventive treatment of pregnant women (IPTp) for malaria with sulfadoxine - pyrimethamine (SP) has since replaced prophylaxis and legislation has been reinforced in the area of insecticide treated mosquito nets (ITNs) in Cameroon. Clinical malaria despite all these measures remains a problem. We compared the socio-obstetrical characteristics of women who developed clinical malaria and those who did not though in the same regimen.

Methods: A 5 - year nested cohort study (2007 - 2011 inclusive) at the tertiary level hospitals in Yaounde. Pregnant women who willingly accepted to participate in the study were enrolled at booking and three doses of SP were administered between 18 - 20 weeks of gestation, between 26-28 weeks and between $32-34$ weeks. Those who developed clinical malaria were considered as cases and were compared for socio - obstetrical characteristics with those who did not. Venous blood was drawn from the women in both arms for parasite density estimation and identification and all the clinical cases were treated conventionally.

Results: Each arm had 166 cases and many women who developed clinical malaria were between 15 and 19 years (OR 5.5, 95\% Cl $3.9-5.3, p<0.001)$. They were of low gravidity (OR 6.5, 95\% Cl $3.8-11.3, p<0.001)$ as well as low parity (OR 4.6, 95\% Cl $2.7-7.9, \mathrm{p}<0.001)$. The cases were single women (OR 4.58, 95\% Cl $2.54-8.26, \mathrm{p}<0.001)$ and had attained only primary level of education (OR 4.6, 95\% Cl $2.8-7.9, \mathrm{p}<0.001)$. Gestational ages were between 20 to 30 weeks during clinical malaria (OR 6.8, 95\% Cl 4.1 - 11.7, $p<0.001)$. The time between the first and second dose of SP was longer than ten weeks in the cases (OR 5.5, 95\% Cl $3.2-9.3, p<0.001)$ and parasite density was higher also among the cases (OR 6.9, 95\% Cl $5.9-12.1, \mathrm{p}<0.001$ ).
\end{abstract}

Conclusion: Long spacing between the first and second dose of SP seemed to be responsible for clinical malaria in the cases.

Keywords: Clinical malaria, Intermittent preventive treatment, Insecticide treated nets

\footnotetext{
*Correspondence: rembu2000@yahoo.com

${ }^{\dagger}$ Equal contributors

'Department of Obstetrics and Gynecology, Faculty of Medicine and Biomedical Sciences, University of Yaounde 1, Cameroon and the Maternity Unit, Central Hospital, Yaounde, Cameroon

Full list of author information is available at the end of the article
} 


\section{Background}

Malaria in pregnancy (MiP) generates public health concerns across the globe, particularly in malaria - endemic settings and results in adverse outcomes both for the woman and foetus [1-5]. Malaria in Cameroon, as it is in other resource restricted countries has a negative impact on the health of children and pregnant women, especially the primigravidae. Indeed, higher susceptibility to malaria is noted among pregnant women probably due to a decrease in their immune responses [6-8].

Management of malaria in pregnancy now combines multiple approaches [9-11]. Some of these approaches include intermittent preventive treatment of pregnant women (IPTp) for malaria using a bimolecular formulation of sulphadoxine - pyrimethamine combined with sleeping in insecticide treated nets (ITNs) [12-15]. These two approaches have been recommended for pregnant women living in endemic areas and are still in use today [16-18]. Effort is being made to scale - up these procedures in Cameroon.

A consensus that favored the use of these approaches was arrived at by the health authorities in Cameroon in the year 2004 and is still in force [19]. Thus, pregnant women are health-provider administered three doses of SP (three tablets per dose) during the course of pregnancy. The first dose is usually administered between the $16^{\text {th }}$ and the $20^{\text {th }}$ week or when the first fetal movements (quickening) are felt. The second dose is administered at least thirty days after the first. This interval is not fixed but is usually between the $26^{\text {th }}$ and the $28^{\text {th }}$ week of gestation and the last dose is between the $33^{\text {rd }}$ and the $34^{\text {th }}$ week. Alongside IPTp, ITNs are distributed freely to pregnant women from booking visits.

Though these procedures form a common package in our antenatal care delivery, clinical cases of malaria among pregnant women constitute about 30 to $40 \%$ of our daily hospital admissions. The aim of this study was to analyze the socio - obstetrical characteristics of cases of clinical malaria and match them against women who did not develop malaria in the same cohort.

\section{Methods}

For a period of five years (2007-2011 inclusive), a cohort of 2525 pregnant women was followed-up from booking to delivery in the outpatient units of three tertiary level hospitals in Yaounde from where clinical cases of malaria and none malaria cases were recruited. These hospitals are all affiliated to the University of Yaounde I, Faculty of Medicine and Biomedical Sciences (FMBS). Women who were HIV infected and those who refused to participate freely in the study were not enrolled. We also eliminated women with fever producing pathologies such as acute pyelonephritis and other confirmed infections.
Enrollment was between 16 and 20 weeks of gestation. Ethical clearance $\mathrm{N}^{\circ} 243 / \mathrm{CNE} / \mathrm{SE} / 2006$ was obtained from the National Ethics Committee and written or verbal consents were also obtained. The women had complete clinical and paraclinical evaluations. Viable pregnancies were confirmed with ultrasound. Three doses of SP were health - provider administered based on updated WHO policy recommendations. They were provided freely with ITNs on enrollment and phone calls and or home visits were carried out to ensure that the women were sleeping under ITNs.

The women were evaluated every visit for evidence of clinical malaria and those who were symptomatic for clinical malaria were hospitalized and treated. Clinical malaria was defined as an acute onset of fever, chills, anorexia, vomiting, muscular or articular pain or both and headache, all these in the absence of any concomitant pathologies such as urinary tract infection and pneumonia. Parasite densities were estimated during symptoms and compared with parasite densities from women who did not have symptoms.

\section{Sample size estimation}

Previous studies indicated that about 30\% of pregnant women develop clinical malaria in Cameroon [20]. This infers, therefore, that the proportion of pregnant women unexposed to IPTp and ITNs who are expected to exhibit the outcome of interest (Po), that is, clinical malaria is 0.3 . We hypothesized that this proportion would be reduced by $50 \%(\mathrm{P} 1=0.15)$ if pregnant women were exposed to both methods and that no participant would leave the study $(f=0)$. Based on these assumptions, the required sample size for the cohort study was 133 rounded up for convenience to 166, $N=\frac{1}{1-f}\left(\frac{2 \times\left(z_{\alpha}+z_{\beta}\right) 2 \times p \times(1-p)}{\left(p_{0}-p_{1}\right) 2}\right)[21]$.

\section{Selection of exposed and unexposed cases}

Cases of clinical malaria (exposed cases) and the rest of the cohort followed up were enrolled in the same period. For each case of clinical malaria enrolled, a pregnant woman recruited at the antenatal clinic who did not present with symptomatic malaria and who was matched for parity and gestational age was enrolled for comparism.

\section{Quantification of serum plasmodium density}

Two weeks after the first dose of SP, thumb prick blood samples were collected for quantification of serum plasmodium densities which served as baseline values for the two groups. We assumed that these D1 parasite densities values would be low after treatment. Subsequently, smears were prepared from the women with clinical malaria as 
well as those who did not (D2 parasite densities) and compared with D1 values.

\section{Microscopy}

Thick blood smears each measuring about $6 \mu \mathrm{L}$ were stained with $10 \%$ Giemsa and examined under the $\times 100$ oil immersion objective lens using Olympus CH30 microscope by two blinded laboratory scientists. Parasite densities were calculated from these thick smears and the thin smears served to differentiate Plasmodium species. The number of asexual parasites was estimated against 200 leucocytes using an average leucocytes count of $8,000 / \mu \mathrm{L}$ as recommended [22]. A smear was considered negative only after 200 high power fields were examined.

\section{Estimation of parasite density}

Parasite densities (parasite/ $\mu \mathrm{L}$ of whole blood) were a ratio of parasites to WBCs in the Giemsa - stained thick smears. Parasites (Plasmodium specy) were counted against $200 \mathrm{WBCs}$. Calculation was as follows:

$=\mathrm{N}^{\circ}$ of parasites counted $/ \mathrm{WBC}$ counted $\times \mathrm{WBC}$ count $/$ $\mu \mathrm{L}$ of participants's whole blood [23].

\section{Treatment of clinical cases}

Confirmed cases were hospitalized for treatment with Quinine Sulphate at $25 \mathrm{mg} / \mathrm{kg} / 24$ hours. Three equi doses were administered daily but not exceeding $1.5 \mathrm{~g} /$ 24 hours irrespective of body weight or body mass index (BMI). Administration was parenteral during the first 72 hours in combination with paracetamol at $60 \mathrm{mg} /$ $24 \mathrm{hrs}$ as adjuvant treatment. From the fourth day, both drugs were administered orally maintaining the same doses for a total duration of treatment of seven days.

\section{Statistical analysis}

Data were entered into spread sheets and analyzed using EPI-Info $^{\text {Tx }}$ version 3.5.1. Parasite densities were calculated based on the hypothesis that parasite densities during clinical malaria (D2) were higher than the initial densities (D1) which were considered as parasite densities before clinical malaria. We calculated odds ratios $(\mathrm{OR})$ and $95 \%$ confidence intervals $(\mathrm{C} 1)$ for the various variables we cross-tabulated that needed comparison between the exposed and unexposed cases. Kruskal-Wallis test was used to estimate the $P$ - values whereby smaller $P$ - values (less than 0.05 ) were considered statistically significant.

\section{Ethical considerations}

Ethical clearance was obtained from the national Ethics Committee and authorization was obtained from the hospital administrations. Data collection did not require any expenditure by the women enrolled and both handling and analysis of data conformed to strict confidentiality.

\section{Results}

A total of 2525 pregnant women were followed up during the study period out of which 166 developed clinical malaria. We selected 166 pregnant women from the same cohort who did not develop clinical malaria and compared their socio-demographic characteristics.

\section{Socio-demographic characteristics}

An equal number of clinical cases were matched against those who did not have symptoms (166 vs 166). Greater proportions of cases were between 15 and 19 years (OR 3.42 , 95\% CI $2.10-5.59$ ) and were of low gravidity (OR $3.77,95 \%$ CI $2.15-6.61$ ) as well as low parity (OR 2.91, $95 \%$ CI 1.68 - 5.01). The cases were single mothers (OR $4.58,95 \%$ CI $2.54-8.26$ ) and educated only at primary level (OR 3.69, 95\% CI 1.58 - 4.58). Gestational ages at the time of attacks were between 20 to 30 weeks in the cases (OR 4.25, 95\% CI 2.45 - 7.37). Time interval between the first and second dose of SP was greater than ten weeks in the cases (OR 5.43, 95\% CI 3.04 - 9.71) (Tables 1 and 2).

\section{Parasite densities}

WBC ranged from 1,700 to 16,000 with a median of 9,300 cells $/ \mu \mathrm{L}$ in clinical malaria cases and from 1,600 to 13,000 with a median of 6,555 cells/ $\mu \mathrm{L}$ in asymptomatic cases. The geometric mean of the parasites, that is $\mathrm{SD}$, were $13,234.5$ and $7,834.7$ ring trophozoites/ $\mu \mathrm{L}$ respectively using the actual WBC count.

\section{Discussion}

Parasitic infections become more severe during pregnancy especially in low resource settings. Women become more susceptible to Plasmodium falciparum (PF) infection during pregnancy. The reason for this remains unclear, but changes in cell-mediated immunity are thought to be involved. Enhanced susceptibility to malaria infection means that when a woman becomes pregnant, she is most likely to develop malaria especially due to PF [24-28].

Clinical symptoms of malaria include fever, chills, sweats, nausea and vomiting [29,30]. All these symptoms were manifested by our patients. Fever occurs when schizonts rupture and release pyrogenic substances. The presence of these substances triggers the over production of cytokins such as interleukin-1 (IL-1), Interlenkin6 (IL-6) and Tumor Necrosis Factor-alpha (TNF- alpha) [31]. These cytokins act on the thermoregulatory center of the hypothalamus, provoking a rise in the internal body temperature leading to fever, chills, shivering, nausea, headache and pain. These symptoms occur following rapid multiplication of the parasite and sequestration of infected RBCs and immune complexes along capillary walls. At this stage, the parasite density is high. We used these symptoms to define clinical malaria in 
Table 1 Demographics of participants

\begin{tabular}{|c|c|c|c|c|c|}
\hline \multirow[t]{2}{*}{ Variable } & \multicolumn{2}{|c|}{ Cohort } & \multirow[b]{2}{*}{ OR } & \multirow[b]{2}{*}{$95 \% \mathrm{Cl}$} & \multirow[b]{2}{*}{ P-value } \\
\hline & $\begin{array}{l}\text { Malaria } \\
\mathrm{n}=166\end{array}$ & $\begin{array}{c}\text { No malaria } \\
\mathrm{n}=166\end{array}$ & & & \\
\hline \multicolumn{6}{|l|}{$\overline{\text { Age }}$} \\
\hline $15-19$ & 64 & 36 & 2.097 & $0.55-3.41$ & 0.036 \\
\hline $20-24$ & 24 & 18 & 1.374 & $1.09-4.02$ & 0.646 \\
\hline $25-29$ & 30 & 25 & 1.275 & $0.69-2.35$ & 0.533 \\
\hline $30-34$ & 20 & 27 & 0.683 & $0.36-1.31$ & 0.324 \\
\hline $35-39$ & 28 & 40 & 0.299 & $0.30-1.37$ & 0.339 \\
\hline \multicolumn{6}{|c|}{ Level of education } \\
\hline Higher & 16 & 21 & 0.704 & $0.32-1.52$ & 0.489 \\
\hline Secondary & 72 & 61 & 1.522 & $0.88-2.62$ & 0.168 \\
\hline Primary & 22 & 28 & 0.732 & $0.39-1.38$ & 0.421 \\
\hline \multicolumn{6}{|c|}{ Marital status } \\
\hline Married & 36 & 33 & 1.127 & $0.56-2.24$ & \multirow[t]{2}{*}{0.771} \\
\hline Single & 74 & 77 & 0.881 & $0.50-1.56$ & \\
\hline \multicolumn{6}{|c|}{ Employment status } \\
\hline Employed & 35 & 27 & 1.434 & $0.79-2.59$ & \multirow[t]{2}{*}{0.294} \\
\hline Unemployed & 75 & 83 & 0.697 & $0.39-1.26$ & \\
\hline \multicolumn{6}{|l|}{ Parity } \\
\hline Primiparous & 58 & 30 & 2.974 & $1.70-5.22$ & \multirow{2}{*}{0.0002} \\
\hline Multiparous & 52 & 80 & 0.336 & $0.10-0.59$ & \\
\hline
\end{tabular}

our cases and we were able to demonstrate a difference in the median WBC counts and geometric mean in the two groups (Table 3). This higher parasite density during clinical malaria is responsible for the blockage or reduction of blood supply to vital organs, a situations

Table 2 Summary of outcomes: clinical vs asymptomatic malaria

\begin{tabular}{|c|c|c|c|c|c|}
\hline Variables & $\begin{array}{c}\text { Clinical } \\
\text { malaria } \\
(n=116)\end{array}$ & $\begin{array}{c}\text { Asymptomatic } \\
\text { malaria } \\
(n=166)\end{array}$ & OR & $95 \%$ IC & $p$ \\
\hline \multicolumn{6}{|l|}{ Maternal age (yrs) } \\
\hline $15-19$ & 68 & 34 & 5.5 & $3.2-9.3$ & 0.000 \\
\hline Gravidity 1 - 2 & 66 & 28 & 6.5 & 3.8-11.3 & 0.000 \\
\hline Parity 1 - 2 & 61 & 32 & 4.6 & $2.7-7.9$ & 0.000 \\
\hline Primary education & 76 & 48 & 4.6 & $2.8-7.8$ & 0.000 \\
\hline $\begin{array}{l}\text { Gestational } \\
\text { age } 20-30 \text { wks }\end{array}$ & 74 & 34 & 6.8 & 4.1-11.7 & 0.000 \\
\hline $\begin{array}{l}\text { Gestational } \\
\text { age }>30 \text { wks }\end{array}$ & 3 & 7 & 0.6 & $0.2-2.4$ & 0.688 \\
\hline $\begin{array}{l}\text { Parasite density } \\
\text { change (\%) }\end{array}$ & 64 & 25 & 6.9 & $3.9-12.1$ & 0.000 \\
\hline \multicolumn{6}{|l|}{$\begin{array}{l}\text { Time between } \\
1^{\text {st }} \& 2^{\text {nd }} \text { dose }\end{array}$} \\
\hline 10 weeks & 68 & 34 & 5.5 & $3.2-9.3$ & 0.000 \\
\hline
\end{tabular}

Table 3 Parasite densities

\begin{tabular}{lcc}
\hline Type of malaria & Median WBC count & Geometric mean \\
\hline Clinical & $9,300 \mathrm{cells} / \mu \mathrm{L}$ & $13,234.5$ ring trophozoites $/ \mu \mathrm{L}$ \\
Asymptomatic & $6,555 \mathrm{cells} / \mu \mathrm{L}$ & $7,834.7 \mathrm{ring}$ trophozoites $/ \mu \mathrm{L}$ \\
\hline
\end{tabular}

likened to thrombotic crisis observed in sickle cell disease (SSD).

The effect of $\mathrm{P}$. falciparum malaria on pregnant women has been assessed in many African countries [32-34]. All the cases we had here were of P. falciparum but mixed species Plasmodium falciparum and Plasmodium ovale malaria have been reported [35]. Results show that PF infection puts both the mother and the fetus at risk. Data from several studies show that there is a higher incidence of anaemia. Anaemia commonly occurs in women in endemic countries and becomes more severe during malaria infection. It results not only from erythrocyte destruction by the parasite, but also from the binding of malaria antigens to the surface of normal erythrocytes which are in turn removed by phagocytosis or complement mediated lyses. Evidence of an association between anaemia and malaria rather than pregnancy-associated anaemia is demonstrated by the fact that there is reduced prevalence of anaemia among pregnant women receiving antimalarial drugs for prophylaxis. Most studies show that the prevalence of malaria parasitaemia in endemic areas significantly increases during pregnancy in comparison to the same women before pregnancy and to their age-matched non-pregnant women. This is mostly marked in primigravid women, with an average 2 -fold increase in prevalence compared to multigravidae [36-39].

Among the one hundred and sixty six (166) women who developed clinical malaria in this study despite IPTp and ITNs, 64 (38.55\%) were between 15 and 19 years and 58 (34.94\%) were in their first deliveries as against 21.69\% and $18.07 \%$ respectively in asymptomatic cases. Both parity and length of gestation have an impact on susceptibility to malaria infection. The susceptibility to infection among non-immune women is similar in all parities [40]. Many arguments have been advanced to explain the increased susceptibility of pregnant women to malaria. However, the clinical manifestations depend on the degree of endemicity of infection in the local environment and the number of weeks of gestation. These largely depend on the intensity and stability of malaria transmission in the area [41].

Education plays a role as women who are not well educated are most likely to live in disadvantageous neighborhoods. A good number of women among the cases were educated at primary school level only $(45.73 \%$ versus $28.92 \%$ ) and gestational age during clinical malaria was between 20 - 30 weeks ( $45.58 \%$ versus $20.48 \%$ ). The level of education did not influence significantly malaria morbidity among the cases and the controls after 
primary level. The occurrence of malaria among women who had attained secondary level of education was similar (OR 1.18, 95\% CI, $0.67-2.09$ ), to those who had university education [OR 1.06, 95\% CI, $0.45-2.25$ ]. One would have expected to find many women within the secondary level of education to have more episodes of clinical malaria as with primary level. However, in a country like ours where $40 \%$ of the population lives below poverty level, our neighborhoods are shared by a population mix where one finds the highly educated alongside those who have not been to school.

Malaria has always been a major public health problem in Yaounde, Cameroon where many cases of P. falciparum malaria occur every day. The prevalence of vector transmission varies from one micro-ecological area to another, resulting in variable levels of transmission [36].

Most of our patients came from the periphery of Yaounde, areas plagued with swampy waters. The bulk of our patients received the second dose of SP at intervals greater than ten weeks. This may be explained by the fact that the second dose of SP was not administered in a uniform manner by our health care providers. In some of the sites, the second dose was administered between the $26^{\text {th }}$ and the $28^{\text {th }}$ week of gestation while in some others; administration was between the $28^{\text {th }}$ and the $30^{\text {th }}$ week of gestation. Be it as it may, the interval between the first and the second dose was rather too long allowing for the effects of the drugs to fade out exposing the women to infection.

The number of cases with clinical malaria declined with increasing gestational age. The prevalence of infection was higher in the first and second trimesters of pregnancy and decreased progressively in the third trimester until delivery as described in literature $[25,26]$. Malaria is among the early pregnancy complications observed among pregnant adolescents in Yaounde [42].

\section{Conclusion}

We conclude that primiparity and long intervals between the first and second dose of SP are responsible for acute bouts of clinical malaria observed among pregnant women who sleep under ITNs in our environment. Young age, low level of education and pregnancies in the first half of gestation also contribute.

\section{Competing interests}

The authors declare that they did not have any competing interests.

\section{Authors' contributions}

REM and HJF conceived and designed the study, drafted the protocol obtained ethical clearance and authorizations to conduct the study in the university affiliated hospitals. FYF and FTN worked with the hospital laboratories, analyzed data, interpreted results and wrote the various portions of the manuscript. RT and WAT were principal investigators respectively in two of the hospitals where the study was carried out. All the authors read and approved the final version of the manuscript and its intellectual and scientific content.

\section{Acknowledgments}

We are thankful to all the workforce of obstetrics and gynecological services of the central hospital, the general hospital, the university teaching hospital and the gynecology and pediatric hospital all in Yaounde for accepting freely to participate in this study. We wish to thank Pr. FX Mbopi - Keou for assistance in ensuring quality control in the laboratories of these hospitals. Our special thanks to the directors and coordinators of the maternity units of these hospitals. We are indeed grateful to the Faculty of Medicine and Biomedical Sciences of the University of Yaounde I for providing resources for this study.

\section{Author details}

'Department of Obstetrics and Gynecology, Faculty of Medicine and Biomedical Sciences, University of Yaounde 1, Cameroon and the Maternity Unit, Central Hospital, Yaounde, Cameroon. ${ }^{2}$ Maternity Unit, Central Hospital Yaounde, Yaounde, Cameroon. ${ }^{3}$ Department of Obstetrics and Gynaecology, Faculty of Health Sciences, University of Bamenda, Cameroon, Bamenda, Cameroon.

Received: 12 June 2013 Accepted: 28 April 2014

Published: 16 May 2014

\section{References}

1. Menendez C, D'Alessandro U, ter Kuile FO: Reducing the burden of malaria in pregnancy by preventive strategies. Lancet Infect Dis 2007, 7:126-135.

2. Guyatt HL, Snow RW: The epidemiology and burden of Plasmodium falciparum - related anaemia among pregnant women in sub - Saharan Africa. Am J Trop Med Hyg 2001, 64:36-44.

3. Elsele TP, Larsen DA, Anglewicz PA, Keating J, Yukich J, Bennett A, Hutchinson P, Steketee RW: Malaria prevention in pregnancy, birthweight, and neonatal mortality; a meta -analysis of 32 national cross-sectional datasets in Africa. Lancet Infect Dis 2012, 12:942-949.

4. Guyatt HL, Snow RW: Malaria in pregnancy as an indirect cause of infant mortality in sub-Saharan Africa. Trans R Soc Trop Med Hyg 2001, 95:569-576

5. Guyatt HL, Snow RW: Impact of malaria during pregnancy on low birth weight in sub-Saharan Africa. Clin Microbiol Rev 2014, 17:760-769.

6. Rosette M, Trine S, Lars H: Cytokine response to pregnancy-associated recrudescence of Plasmodium berghei infection in mice with pre-existing immunity to malaria. Malar J 2013, 12:387.

7. Helle HH, Jorgen AK, Bamenla QK, Onike PR, Francis NN, Thor GT, Michael A: Human genetic polymorphism in the knops blood group are not associated with protective advantage against Plasmodium falciparum malaria in south Ghana. Malar J 2013, 12:400.

8. Taylor RR, Allen SJ, Greewood BM, Riley EM: IgG3 antibodies to plasmodium falciparum merozoite surface protein 2 (MSP2): increasing prevalence with age and association with clinical immunity to malaria. Am J Trop Med Hyg 1998, 58:406-413.

9. Hugue C, Johann C, Sophie M, Martine B, Nadine G, Paul-Henri C: Atovaquoneproguanil in the treatment of inported uncomplicated Falciparum malaria: a prospective observational study of 553 cases. Malar J 2013, 12:399.

10. Oluwaseun $E$, Kazeem AO: Comparative safety of artemether-lumefantrine and other artemisinin-based combinations in children: a systemic review. Malar J 2013, 12:385

11. Michelle SH, Jimee H, Amy RT, Yaoboa L, Adam B, George S: Mass drug administration for the control and elimination Plasmodium vivax malaria: an ecological study from Jiansu province. China Malar J 2013, 12:283.

12. Menéndez C, Bardaji A, Sigauque B, Sanz S, Aponte JJ, Mabunda S, Alonso PL: Malaria prevention with IPTp during pregnancy reduces neonatal mortality. PLOS ONE 2010, 5:e9438.

13. Gutman J, Mwandama D, Wiegand RE, Ali D, Mathanga DP, Skarbinski J: Effectiveness of intermittent preventive treatment with sulfadoxine pyrimethamine during pregnancy on maternal and birth outcomes in Mchinga district, Malawi. J Infect Dis 2013, 208:907-916.

14. Hill J, Kazembe P: Reaching the Abuja target for intermittent preventive treatment of malaria in pregnancy in African women: a review of progress and operational challenges. Trop Med Int Health 2006, 11:409-418

15. Mubyazi G, Bloch P, Kamuggisha M, Kitua A, ljumba J: Intermittent preventive treatment of malaria during pregnancy: a qualitative study of 
knowledge, attitudes and practices of district health managers, antenatal care staff and pregnant women in Korogwe district, North-East Tanzania. Malar J 2005, 4:31.

16. Holtz TH, Kachur SP, Roberts JM, Marum LH, Mkandala C, Chizani N, Macheso A, Parise ME: Use of antenatal care services and intermittent preventive treatment for malaria among pregnant women in Blantyre District, Malawi. Trop Med Int Health 2004, 9:77-82.

17. Nganda RY, Drakeley C, Reyburn H, Marchant T: Knowledge of malaria influences the use of insecticide treated nets but not intermittent presumptive treatment by pregnant women in Tanzania. Malar J 2004, 3:42.

18. Filémon $\Pi$, Aurore $\mathrm{HO}$, Yolande $\mathrm{S}$, Arthur S, Virgile $\mathrm{G}$, Sylvie C: Impact of long-lasting, insecticidal nets on anaermia and prevalence of Plasmodium falciparum among children under 5 years in areas with highly resistant malaria vectors. Malar J 2014, 13:75.

19. Ministry of Public Health $(\mathrm{MoH})$ Cameroon: National policy on the control of malaria. Report of the national program for the fight against malaria. Cameroon: MoH; 2004.

20. Rose FGL, Rosine RD, Mbu RE, Leke RJl, Fogako J, Megnekou R, Metenou S, Sama G, Zhou Y, Cadigan T, Parra M, Taylor DW: Detection of the plasmodium falciparcem antigen Histidine - Rich protein 2 in blood of pregnant women: implications for diagnosing placental Malaria. J Clin Microbiol 1999, 37(9):2992-2996.

21. WHO/HRP/EPI: An epidemiological approach to reproductive health. WHO/ HRP/EPI Report; 1994:164-165.

22. Trape JF: Rapid evaluation of malaria parasite density and standardization of thick smear examination for epidemiologic investigations. Trans R Soc Trop Med Hyg 1985, 79:181-184.

23. AbdElrahim DH, Leana ME, Gamal KA, Duria AR, Ishag A: Estimating malaria parasite density among pregnant women at central Sudan using actual and assumed white blood cell count. Malar J 2014, 14:6.

24. Tagbor H, Bruce J, Browne E, Greenwood B, Chandramoban D: Malaria in pregnancy in an area of stable and intense transmission: is it asymptomatic? Trop Med Int Health 2008, 13:1016-1021.

25. Halayne MS, Doncan SL, Tim AS, Lu ML: Malaria infection during pregnancy. Inf Dis Clin N Am 1997, 11(1):99-103.

26. Roth I, Troll P, Sweeze M: Human placental cytotrophoblasts produce the immunopsuppressive cytokine interleukin 10. J Exp Med 1996, 184:539-548.

27. Lamardeley P, Maiga J, Charbon R, Keuzeta JJ, Foumanne V, Chandenier J: Prevention of malaria among pregnant women in an urban setting (Yaounde Cameroon). Cahier Santé 1999, 7:239-245.

28. Rahhupathy R, Hung G, Tell F: Th 1 - type immunity is incompatible with successful pregnancy. Immuno Today 1977, 18(10):478-482.

29. Patricia B, Anielle PC, Cecilia LL, da Silva S, Maria FF, Claudio TD: Malaria, a difficult diagnosis in a febrile patient with sub-microscopic parasitaemia and plyclonal lymphocyte activation outside the endemic region in Brazil. Malar J 2013, 12:400.

30. Julia G, Aboubacar M, Halima Z, Mariama K, Ibrahim A, Maman LI: Epidemiology of malaria in an area of seasonal transmission in Niger and implications for the design of a seasonal malaria chemoprevention strategy. Malar J 2013, 12:379.

31. Mubert B, Fievét N, Tami G, Cot M, Boudin C, Delron P: Development of antibodies against chondroitin sulfate $A$ - adherent plasmodium falciparum in pregnant women. Infect Immun 1999, 67(10):5367-5371.

32. Guoling XI, Leke Rose GE, Thuita LW, Ainong Z, Leke Robert Jl, Mbu R, Taylor DW: Congenital exposure to plasmodium falciparum antigens; prevalence and antigenic specificity of in utero produced anti malarial immunoglobalin M antibodies. Infect Immun 2003, 71(3):1242-1246.

33. Rose FG, Leke R, Timothy JC, Mbu R, Robert IJL, Josephine F, Rosetto M: Plasmodium falciparum in pregnant Cameroonian women: an assessment of changes in the placenta of low birth weight infants. J Cam Acad Sci 2002, 2:203-212.

34. Mbu RE, Dsamo Tantchou MSP, Fomulu JN, Tonye RN, Nana PN, Ako SN, Eteki NT, Leke RJ: Variation of plasma plasmodium density among women receiving sulphadoxine pyrimethamine for intermittent preventive treatment of Malaria during pregnancy. CMCH 2005, 2(2):351-353.

35. Heather S, Nadia A, Andrea KB, Shaun KM: Mixed - species Plasmodium falciparum and Plasmodium ovale malaria in a paediatric returned traveler. Malar J 2014, 13:78.
36. Quakyi IA, Leke RFG, Befidi-Mengue R, Tsafack M, Bomba-Nkolo D, Manga $L$ : The epidemiology of plasmodium falciparum in two Cameroonian villages: Simbock and Etoa. Am J Trop Med Hyg 2000, 63(5):220-230.

37. O'Neil-Dunne I, Rajeshwara NA, Agbor-Enoh ST, Valiyaveettil M, Naik RS, Okenhouse CF, Leke RG: Gravidity - dependent production of antibodies that inhibit the binding of plasmodium falciparum erythrocytes to placental chrondroitin sulfate proteoglycan during pregnancy. Infect Immun 2001, 69(12):7487-7492.

38. Stealsoe T, Megnekou R, Fievét N, Ricke H, Zoming D, Leke RJI, Lege RG, Diana WT: Acquisition and decay of antibodies to pregnancy associated variant antigens on the surface of plasmodium falciparum infected erythrocytes that protect against placental parasitaemia. $J$ Infect Dis 2001, 184:618-626.

39. Bouvier $P$, Doumbo $O$, Breslow $N$, Robert CF, Mauris A, Picquet M, Kouriba B, Keita D, Delley $V$, Rougemont A: Seasonality, malaria and impact of prophylaxis in a West African village: effect of anemia in pregnancy. Am J Trop Med Hyg 1997, 56(4):803-815.

40. Blair JW, Linda K, Mwayi M, Albert M, Abbey M, Bonus M: Gestational age assessment in malaria pregnancy cohorts: a prospective ultrasound demonstration project in Malawi. Malar J 2013, 12:183.

41. Aribot G, Roger C, Sarthou JL, Trape JF, Balde AT, Druilhe P, Roussilhou C: Pattern of immunoglobulin isotype to plasmodium falciparum blood stage antigens in individuals living in holoendemic area of Senegal. Am J Trop Med Hyg 1996, 54(3):449-457.

42. Ako SN, Mbu R, Nana P, Tonye R, Eteki N, Leke RJ: Early pregnancy complications among adolescents admitted in the central maternity of the Yaounde central hospital. Cameroon J de la SAGO 2003, 4(1):26-35.

doi:10.1186/1472-6874-14-68

Cite this article as: Mbu et al: Clinical malaria among pregnant women on combined insecticide treated nets (ITNs) and intermittent preventive treatment (IPTp) with sulphadoxine-pyrimethamine in Yaounde, Cameroon. BMC Women's Health 2014 14:68.

\section{Submit your next manuscript to BioMed Central and take full advantage of:}

- Convenient online submission

- Thorough peer review

- No space constraints or color figure charges

- Immediate publication on acceptance

- Inclusion in PubMed, CAS, Scopus and Google Scholar

- Research which is freely available for redistribution

Submit your manuscript at www.biomedcentral.com/submit
C Biomed Central 